\title{
北欧水域におけるデツカ航法図について
}

\section{On the "Decca Navigation Chart" in the Northern European Waters}

\author{
並川 能 正（神戸商船大学） \\ 樽美幸雄 ( " ") )
}

\begin{abstract} formulae:

$$
\begin{aligned}
& P(\mathrm{P}, \mathrm{R})=\quad \sin \phi_{P}+\sin \phi_{R}-\sin \left(\phi_{P}+\phi_{R}\right) \\
& P(\mathrm{P}, \mathrm{G})=\frac{3}{4}\left\{\sin \phi_{P}+\sin \phi_{G}-\sin \left(\phi_{P}+\phi_{G}\right)\right\} \\
& P(\mathrm{R}, \mathrm{G})=\frac{3}{5}\left\{\sin \phi_{R}+\sin \phi_{G}-\sin \left(\phi_{R}+\phi_{G}\right)\right\}
\end{aligned}
$$
\end{abstract}

First we drew the contours of the constant probability density of the ship-position every each existent Decca Chain in the Northern European Waters, using the following

[See Fig. $2 \sim$ Fig. 9 in this paper]

Secondly, by means of the combination of the above mentioned contours, we made the practical "Decca Navigation Chart" by which we could select the appropriate chain and pair to find out the most accurate Decca Fix at any position in the ditto Waters.

[See Fig. 10 in this paper]

\section{1. 緒言}

確率密度を求める公式により、北欧水域における各デッカチエーンのそれぞれの組局につい て、確率密度等価線図を描き、乙れら組合せて同水域におけるデッカ船位の確率密度勢力分布 を示し、併せて利用組局の選定に便宣を与えるデツカ航法図を作製した。

\section{2. 一つのチエーンについての確率密度等価線図}

今例えば Purple 局と Red 局とによる組局を(P, R) のように表わし、船位がそれぞれの基 線に対して張る角を $\phi_{P} 、 \phi_{R}$ をつて表わすととにすれば、その組局についてのデッカ船位の 確率密度は常数を適当に定めることにより

$$
P(\mathrm{P}, \mathrm{R})=\sin \phi_{P}+\sin \phi_{R}-\sin \left(\phi_{P}+\phi_{R}\right)
$$

で与えられる。

他の二組の組局 $(\mathrm{P}, \mathrm{G})$ 及び $(\mathrm{R}, \mathrm{G})$ についてる同様に考元、比較周波数の相違を考慮に入れ ると、基線上の中央誤差にしたがつてそれぞれ $\frac{3}{4}$ 及び $\frac{3}{5}$ るる精度比を乗し、その確率密度は

$$
P(P, G)=\frac{3}{4}\left\{\sin \phi_{P}+\sin \phi_{G}-\sin \left(\phi_{P}+\phi_{G}\right)\right\}
$$


$P(\mathrm{R}, \mathrm{G})=\frac{3}{5}\left\{\sin \phi_{R}+\sin \phi_{G}-\sin \left(\phi_{R}+\phi_{G}\right)\right\}$

のようになる1”。

北欧水域をカバーしているデッカチエーンは次表に示す８チエーンである。

今との中からチエーン番号(1)の South-West British Chain について、(1)、(2)、(3) 式によ

り各組局毎の確率密度等価線を描いたものが第 1 図である。

これら 3 者を組合せて等価線を互いに連結し、その連結点を結んで、高精度の船位を得るため

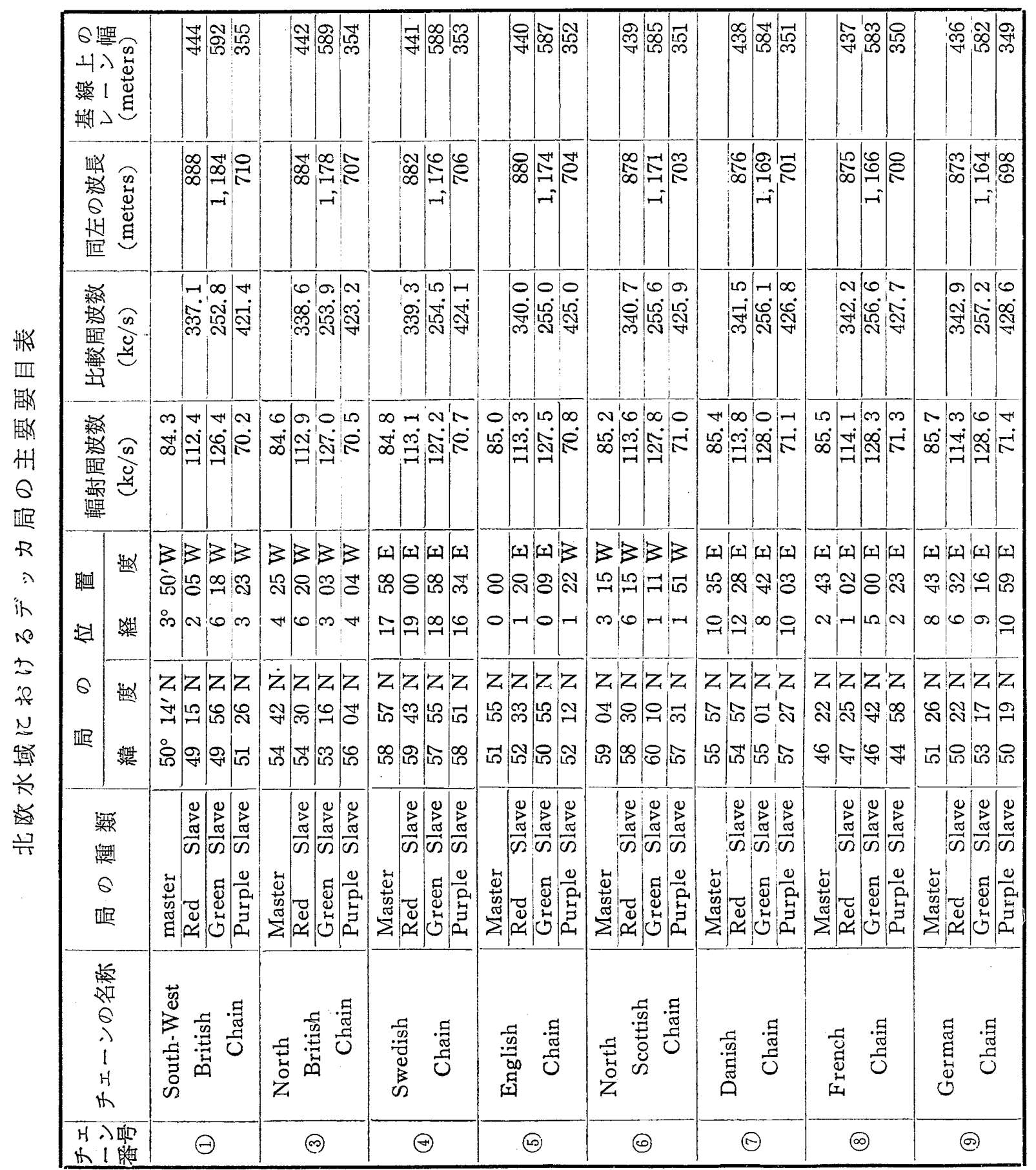

1)、2）これらについては、並川・樽美「デッカ航法の確率密度等価線図について」（日本航海学会誌第 22 号、昭和 35 年 3 月）に詳しい。 
に採用すべ意組局の境界線を明らかにしたものが第 2 図である。

\section{3. デッカ航法図}

第 3 図以下第 9 図に至る一連の図は符 2 図と问じ要領で描いた残りクチエーンの等伍線図であ る。

てれらの図を面に組合せて、北欧全水域に互り隣接デエーンの等価線遭結点を結んだものが第 10図である。

第10図は同水域におけるデッ力船位の確率密度勢力分布を点線をもつて示すと同時に、その分

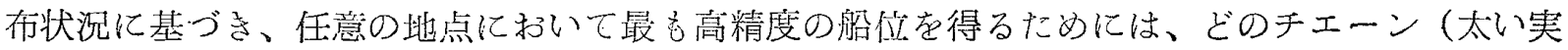
線によつて区分）のどの組局（細い実線によつて区分）を選ぶべきであるかる示している。

もつとも本図によつて組局を選定するにあたつては、「基線の延長線方向にできている鍥状の 区劃内においては最も近い従局を含まない組局（即ち反対側の組局）を利用する」という基本事 項2を心得ていなければならない。

な打船船専用の図としては陸上に互る部分は不要なわけであるが、利用区域の境界線がかなり 複雑な点を勘案し、更に航空機航法における利用をも考慮して、陸上部分の図をあえて抹消せず に残しておくことにした。

又主局からの距離が 240 理を超光れば精度がかなり低下することがいわれているが、デッカの サービス区域そのものが比較的小範眀であるから、全体的に見て距離の制限に固執する必要はあ まりないと思われ、あまつさえデッカチャートには2 40 浬以上の範团についても一応ラティスラ インが描かれているので、本図にはての意味の境界線は設けないことにした。
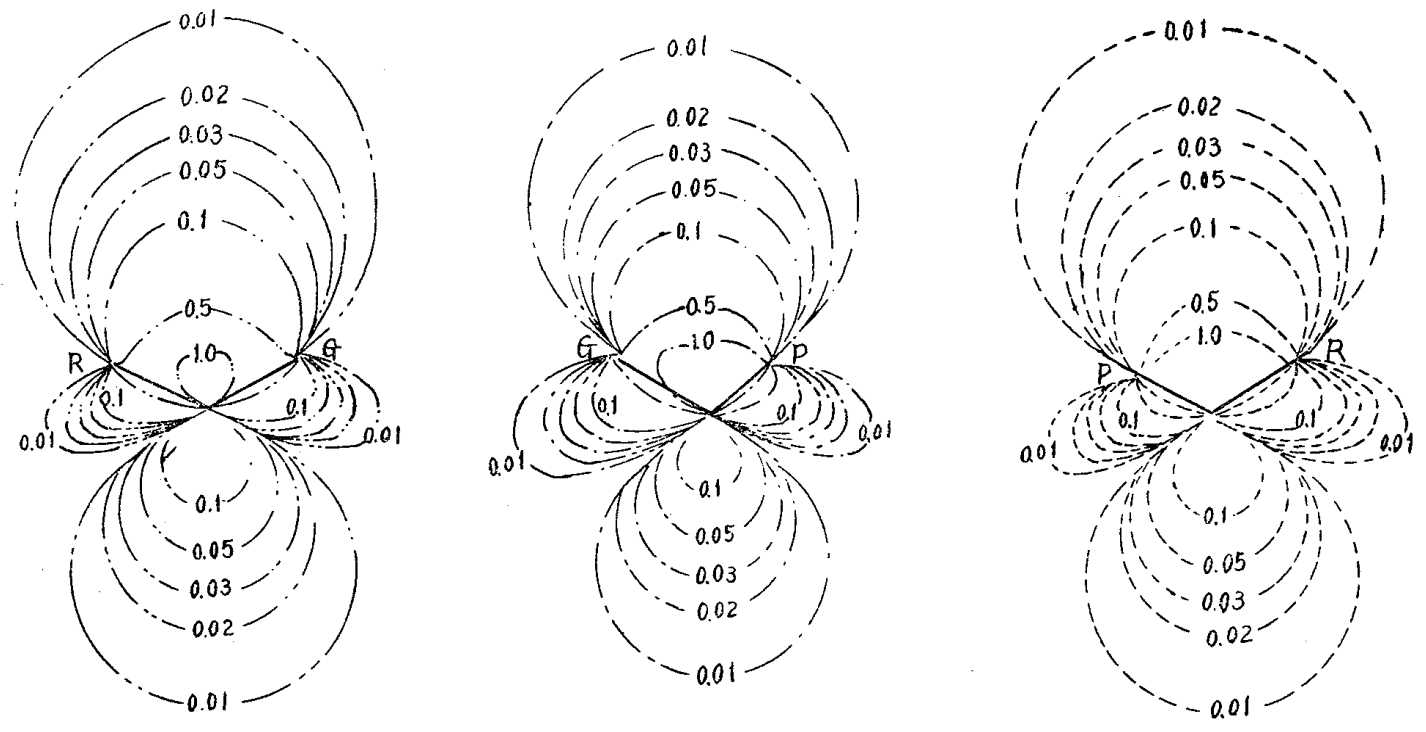

第1図 South-West British Chain (Chain 1) 


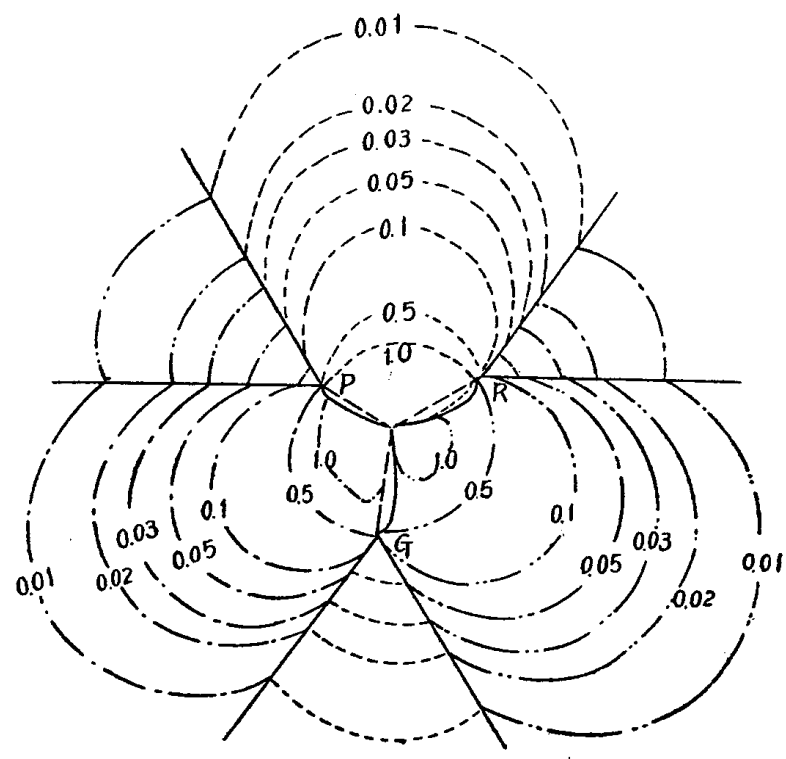

第 2 図 South-West British Chain (Chain 1)

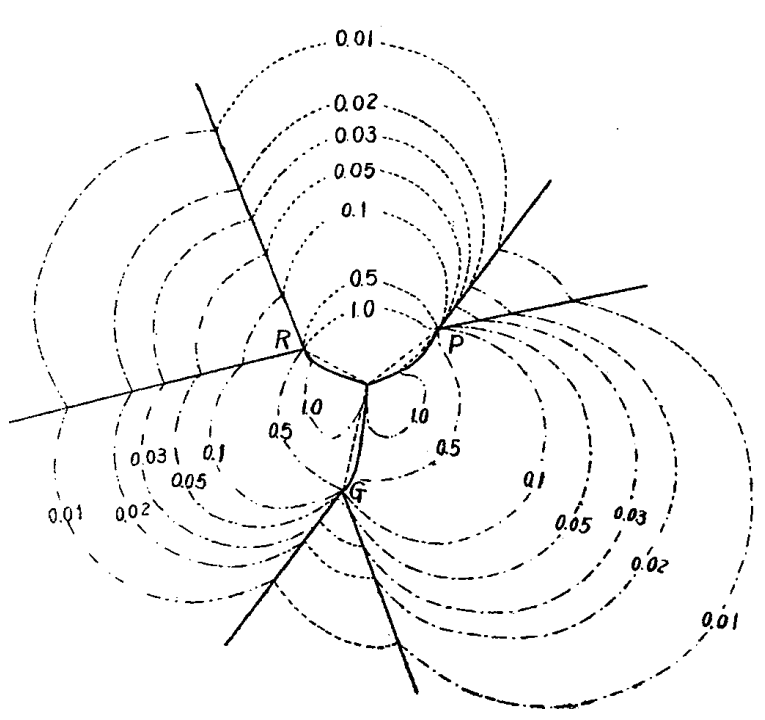

第 3図 North British Chain (Chain 3)

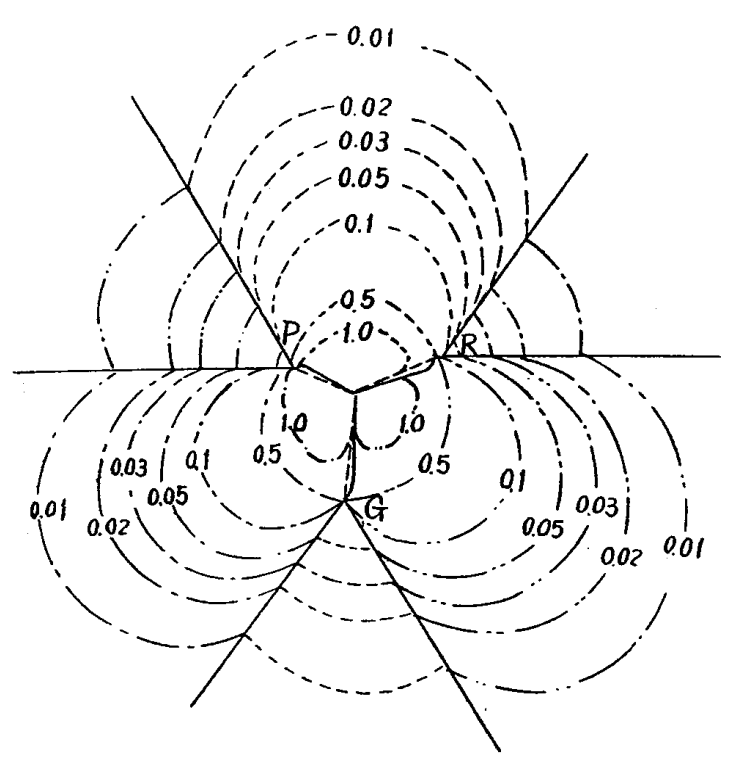

第 4 図 Swedish chaih (Chain 4)

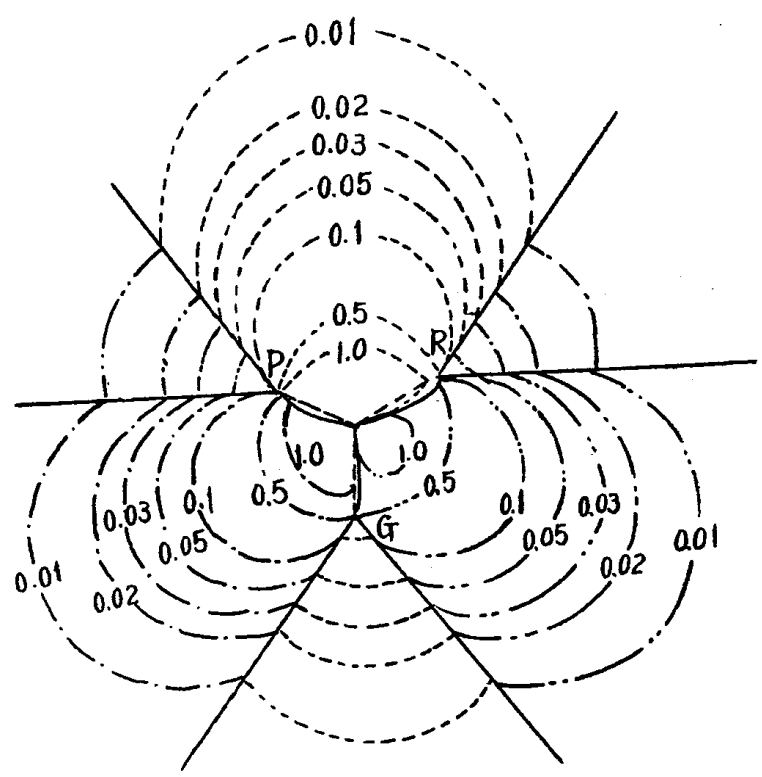

第5図 English Chain (Chain 5) 


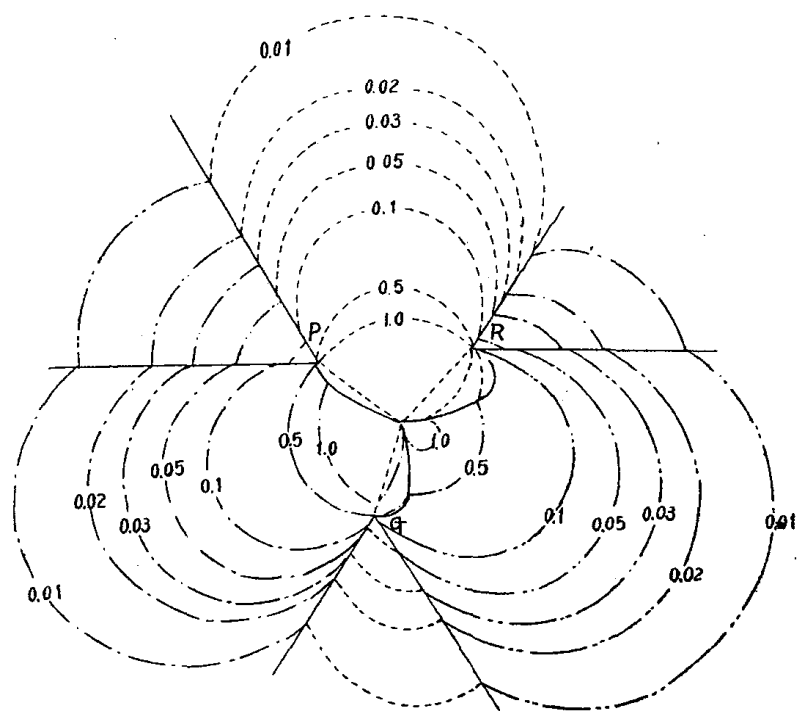

第6図 North Scottish Chain

(Chain 6)

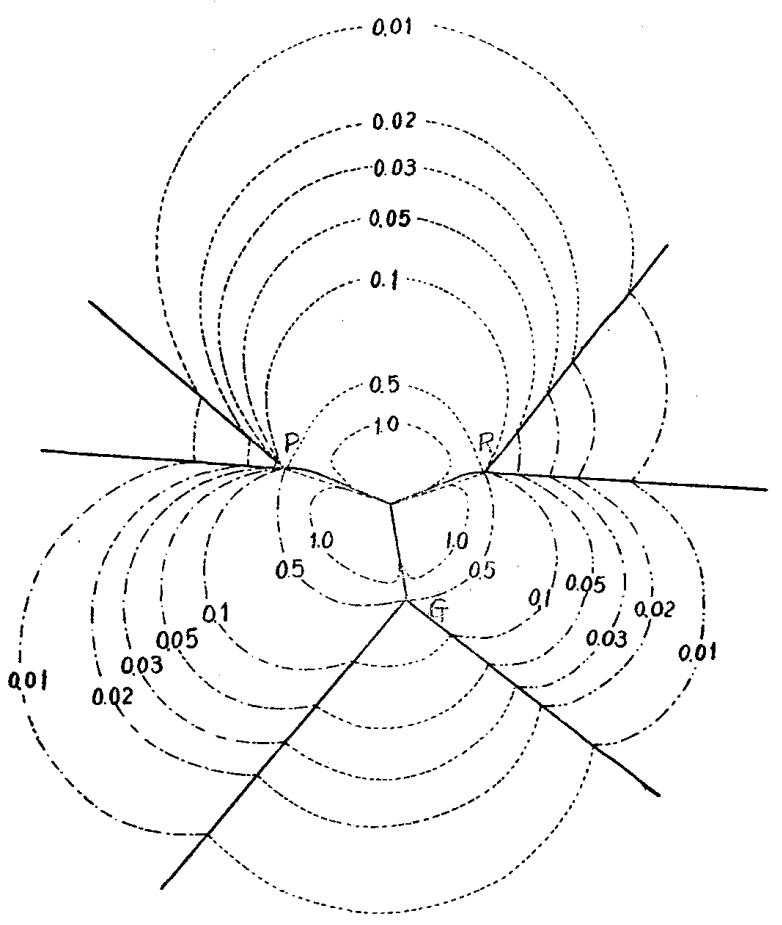

第7図 Danish Chain (Chain 7)

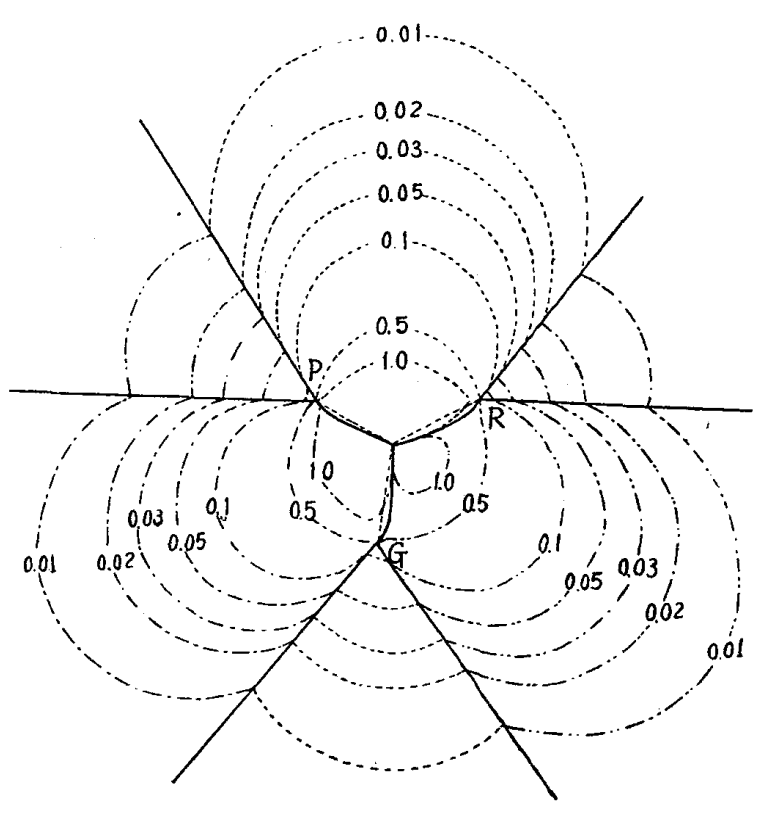

第8図 French Chain (Chain 8)

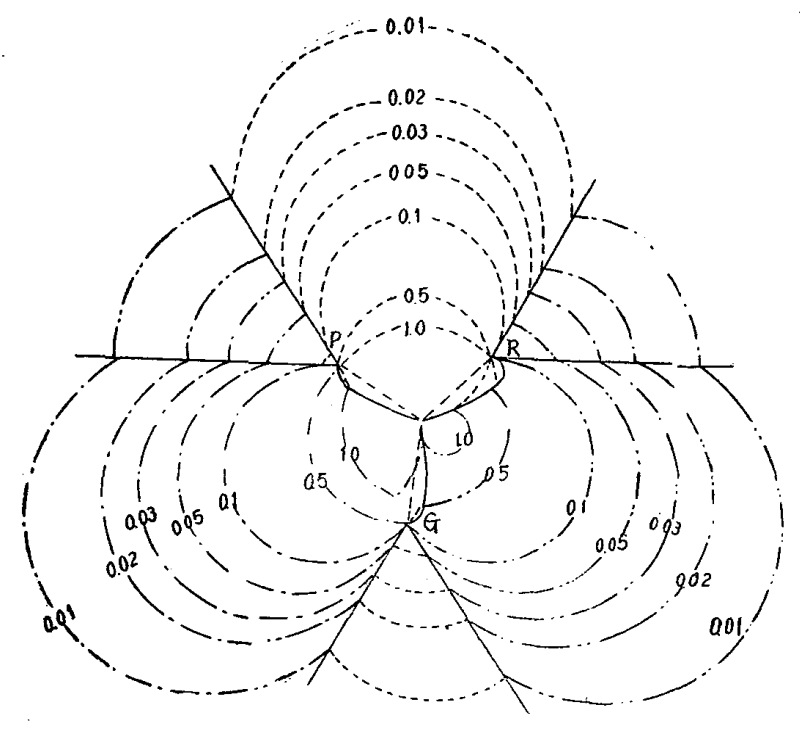

第9図 German Chain (Chain 9) 


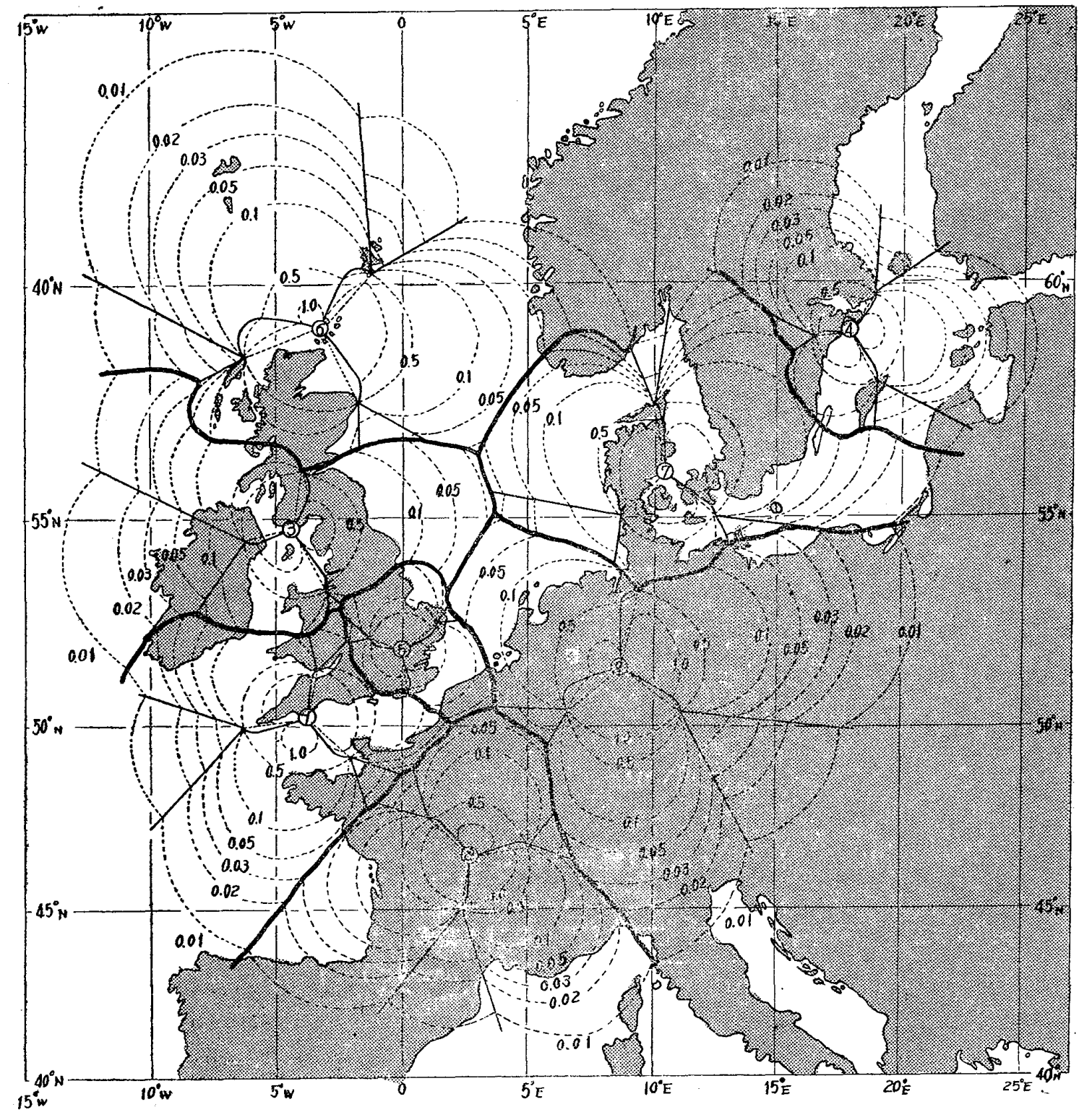

第 10 図 北欧水域におうりるデッカ航法図 


\section{4. 結 言}

この航法図によく似たものに英国の水路部から参考図 5043 号として出されている Decca Fixing Accuracy Diagram がある ${ }^{3)}$ 。もつともこれは第10図のような航法図ではないから組哬 選定のための境界線は描いてなく、単なる等精度曲線を示した図である。

但し両者についてての等精度曲線のみを比較した場合、その形状に多少の相違が見られる。 おそらくこれは上記 Diagram が、所謂円形誤差界の面積が等しい点（即ちその半径が等しい 点）を連ねる曲線をもつて等精度曲線としているためであろうと思われる。

本図における等精度曲線は、船位の存在確率が等しい点即ち船位についての槁円形誤差界の面 積が等しい点を連ねた曲線である4 。

なお本図においては、円形愦差界の方では考慮することが難しいと考えられるレーン幅の相違 による精度比を利用して、等精度曲線の確度を更に向上している。

この図が北欧水域の航行に際し、デッカ船位の測定にあたつて、いくらかでも参考となればま ととに幸甚である。

稿を終るにあたつつて、本研究に関し貴重な資料をいただいた海上保安庁灯台部の福帛弘氏に対 し誌上厚く謝意を表します。

〔参考文献〕

脚註に揭げたものの外に

(1) 海上保安庁：デッカ技術資料(1)、炤和35年

(2) H, M. Stationery Cffice : Admiralty Manual of Navigation Vol. I, 1954.

(3) Decca Navigator Co. Ltd. : Marine Data Sheets, 1957.

3)この図は Radio Signals Vol. V (Hydrographic Department Admiralty, 1958) の巻末に考輯録さ れている。

4) これら雨等精度曲線の比輘については、並川・長谷川「ローラン航法図について」（神戸商船大学紀要 航海機関学篇第 3 号、昭和 31 年 3 月）に詳しい。 